\title{
Five years on
}

\author{
With this issue, we are celebrating the fifth anniversary of the launch of Nature Geoscience - a good \\ time to look at some numbers.
}

For five years, Nature Geoscience has accompanied the evolution of the Earth and planetary sciences. It has been an exciting time, both for us editors and for the scientific community. To reflect on the eventful half-decade that has gone by, we are pleased to present on page 7 a series of essays, written by leading geoscientists, that look back at some of the most incisive shifts in perspective since our call for papers in 2007. And, to celebrate, we have assembled our ten favourite Nature Geoscience articles in a web focus (http://www.nature.com/ngeo/focus/5thanniversary/index.html). Finally, we would like to share with our readers some facts and figures with respect to our editorial activities and submissions.

First, spurred on by Nature's analysis of their own sexism (Nature 491, 495; 2012), we too have taken a look at the gender balance of our referees and authors of our commissioned articles. So far, about $18 \%$ of our referees and $23 \%$ of our lead News and Views authors have been female. Both ratios compare favourably with those at Nature, where, in the geosciences in 2010 and 2011, $14 \%$ of referees and an extremely low $4 \%$ of News and Views authors were women. Nevertheless, these numbers probably under-represent the proportion of talented women working in the Earth sciences. And we're doing less well when it comes to Review or Progress Articles, with only $17 \%$ of authors female, or Commentaries and Features, where the percentage of lead women authors falls to $10 \%$.

In the US, women represent a mere $26 \%$ of assistant professors, $14 \%$ of (tenured) associate professors and $8 \%$ of full professors (Nature Geosci. 1, 79-82; 2008), and proportions in other countries with a large scientific output are probably not a huge way off these figures. These are the academic groups from which we recruit most of our commissioned authors and referees. We will endeavour to provide more opportunities for bright female scientists, beyond their representation in the academic establishment, to help raise their participation. But at least we are not too far off gender ratios in the pool of potential authors and referees.

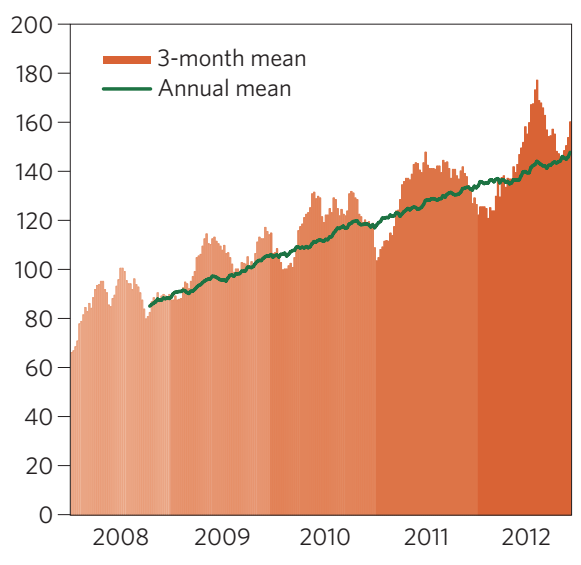

Monthly submissions to Nature Geoscience. Averaged over a year, monthly submissions have risen almost linearly over the five years since launch (green, sum of submissions over the preceding 52 weeks divided by 12). Three-month averages show a distinct seasonal cycle (orange, sum of submissions over the preceding 13 weeks divided by 3 ).

In terms of manuscript submissions, we have seen an almost linear rise over the five years since our launch, averaged over a full year (Fig. 1). All in all, submissions have almost doubled. As in many Earth science data sets, there is a strong seasonal cycle superimposed on this linear trend, although in this case more societally driven: quiet periods show up at the end of the year and occasionally in late summer, when many go on field work or holidays.

A few wrinkles in the record illustrate how our submission rates reflect the world of geoscientists (and sometimes, the world at large). We attribute the sharp peak around the end of July 2012 to the deadline for submission of manuscripts to be considered for the fifth assessment report of Working Group I of the Intergovernmental Panel on Climate Change. And the number of incoming papers dropped during fall meetings of the American Geophysical Union - and during football world cups.

Despite the rise in submissions over the past five years, the number of published papers has expanded only modestly. From 122 primary research papers in 2008 , the journal has evolved to publish 134 papers in 2012. That means, of course, that the accept rate has declined over time. As the journal has become more established, editors and referees together have raised the bar for what a paper in Nature Geoscience should achieve.

So far, we have received 7,426 manuscripts since our call for papers, and we have roughly halved the rate of submissions sent out for review. These are the papers that we editors deem potentially suitable for publication in Nature Geoscience in terms of novelty and importance (provided the claims are confirmed to be robust in peer review). In 2007, before launch, we received 396 manuscripts, and sent 142 , or $36 \%$, out for review. In 2012, 1,662 manuscripts had been submitted by the time of writing, and we obtained referee advice on 390 of them, about $18 \%$.

Our decision-making is assisted by a broad base of the community who have acted for us as referees: we have received reports from more than 3,400 distinct referees. Because we are keen to distribute the workload as well as the responsibility that comes with peer review among researchers, we try to give all our referees reasonable breaks between requests to review. As a result, the single most frequently used referee has helped with no more than nine distinct manuscripts (not counting revisions), less than two per year on average. The next busiest referee looked at seven distinct papers for us, followed by three referees who have seen six, and five who have seen five papers.

The Earth is changing rapidly, not least as a result of human activities. The Earth sciences are evolving too, as new tools, methods and data are generated. And the world of scientific publishing is in fast flux. With the continued support of the Earth and planetary science community, we hope to contribute to progress in all three areas, while endeavouring to serve research by delivering a spectrum of interesting papers each month that will inspire our readers. 